\title{
Efficacy of Occlusion Therapy for Management of Amblyopia in Children age Older than Six Years
}

Dr. Sonalee Mittal*, Dr. Dinesh Mittal

Drishti The Vision Eye Hospital Vijaynagar Indore, Indore, Madhya Pradesh 452010, India

DOI: $10.36347 /$ sjams.2020.v08i11.030

| Received: 05.11.2020 | Accepted: 18.11.2020 | Published: 23.11.2020

*Corresponding author: Dr. Sonalee Mittal

Abstract

Original Research Article

Purpose: To Analyze results of Part Time or Full Time Occlusion Therapy for Amblyopia in children older than 6 years. This was a retrospective consecutive case series analysis of children treated for amblyopia in the Drishti the Vision Eye hospital Indore from January 2018 to January 2020. Materials and Methods: This was a retrospective consecutive case series analysis of children treated for amblyopia at Drishti the Vision eye hospital at Indore. All children received part time or full-time occlusion for the dominant eye. Results: Sixty-eight children older than 6 years at the time of initiation of therapy were included. Age at initiation of therapy ranged from 6 to 14 years. Thirty-two children had Strabismic Amblyopia, 27 had Anisometropic Amblyopia and 9 had a combination of Strabismic and Anisometropic Amblyopia. Fifty out of 68 eyes had improvement in visual acuity following occlusion Therapy. Conclusion: Occlusion therapy yields favorable results in Strabismic and/or Anisometropic Amblyopia, even when initiated for the first time after 6 years of age. Both Full time and part time occlusion therapy are successful. The chances of success decrease as the age at when the occlusion therapy is given increases. The chances of success are more with full time occlusion.

Keywords: Amblyopia, occlusion, dominant eye.

Copyright $\odot 2020$ The Author(s): This is an open-access article distributed under the terms of the Creative Commons Attribution 4.0 International License (CC BY-NC 4.0) which permits unrestricted use, distribution, and reproduction in any medium for non-commercial use provided the original author and source are credited.

\section{INTRODUCTION}

Amblyopia is defined as Binocular or Monocular decrease in Best Corrected Visual Acuity (BCVA) due to Form Vision Deprivation and/or Abnormal Binocular Interaction for which there is no obvious ocular pathology or visual pathway defect and which in appropriate cases is reversible.

Strabismic Amblyopia results from competitive or inhibitory interaction between neurons carrying non fusible input from the two eyes. In young children with strabismus, suppression develops rapidly. This visual adaptation serves to avoid diplopia and visual confusion. Constant suppression of input from the same eye can lead to amblyopia.

In Anisometropic Amblyopia, dissimilar refractive errors in the two eyes cause one retinal image to be chronically defocused.

The least common form of amblyopia, but the most severe and difficult to treat, is Visual Deprivation Amblyopia (also known as Stimulus Deprivation Amblyopia, and Form-Vision Deprivation Amblyopia), which is due to an eye abnormality that obstructs the visual axis or otherwise interferes with central vision. The most common cause is congenital or early-acquired cataract; other causes include blepharoptosis, periocular lesions obstructing the visual axis, corneal opacities, and vitreous hemorrhage. Visual deprivation amblyopia develops faster, and is deeper, than strabismic or anisometropic amblyopia.

Treatment of amblyopia involves the following steps:

1. Eliminate any obstruction of the Visual Axis, such as a cataract.

2. Correct any significant Refractive Error.

3. Promote use of the Amblyopic Eye.

Refractive Correction plays a key role in the treatment of all types of Amblyopia. Anisometropic, Iso Ametropic, and even Strabismic Amblyopia may improve or resolve with refractive correction alone. Many ophthalmologists thus initiate amblyopia treatment with refractive correction, adding occlusion or pharmacologic or optical treatment later if necessary. Refractive correction for aphakia following cataract surgery in childhood is initiated promptly to avoid prolonging visual deprivation. In general, refractive correction in amblyopia should be based on the cycloplegic refraction. Often, full hyperopic correction 
is necessary to treat coexisting accommodative esotropia.

Occlusion Therapy (patching) is commonly used to treat unilateral amblyopia. The sound eye is covered, obligating the child to use the amblyopic eye. Adhesive patches are usually employed. Usually FullTime Occlusion, defined as occlusion during all waking hours, is preferred for treatment of amblyopia. PartTime Occlusion of six hours per day may achieve results comparable to those obtained with prescribed Full-Time Occlusion. The relative duration of patch-on and patch-off intervals should reflect the degree of amblyopia. For severe deficits Full Time Occlusion is preferred. For moderate deficits six hours of daily patching may be effective. It is not necessary for the patient to engage in specific activities (e.g. near work) while patched. The desired endpoint of therapy for unilateral amblyopia is Free Alternation of Fixation and/or linear recognition acuity that differs by no more than one line between the two eyes. The time required to complete treatment depends on amblyopia severity, treatment intensity, and patient compliance and age. More severe amblyopia and older children require more intensive or longer treatment.

Alternatives to occlusion therapy involve Pharmacologic and/or Optical degradation of the vision of better eye so that it becomes temporarily inferior to the vision of amblyopic eye, promoting use of the amblyopic eye. A Cycloplegic agent (usually Atropine sulfate $1 \%$ solution) is administered to the better-seeing eye so that it is unable to accommodate. Pharmacologic treatment is difficult for the child to thwart. Parents should be counselled regarding the adverse effects of atropine, including light sensitivity, and potential systemic toxicity, the symptoms of which include fever, tachycardia, delirium, and dry mouth and skin. Optical treatment involves the prescription of excessive plus lenses (fogging) or diffusing filters for the sound eye. This form of treatment avoids potential pharmacologic adverse effects and may be able to induce greater blur than cycloplegic agents.

Occlusion of the non-amblyopic eye is the most commonly used treatment for children with amblyopia [1]. The response to amblyopia therapy is related to type of amblyogenic stimulus, initial depth and duration of amblyopia, age at initiation of therapy, method of amblyopia treatment and compliance [2]. Reports of children treated for anisometropic and strabismic amblyopia continue to suggest that occlusion therapy yields better response to treatment up to 6 to 7 years of age [3, 4]. Flynn et al., reviewed the results of amblyopia therapy using pooled data from 961 children described in 23 published studies between 1965 and 1994 and observed that the single factor that most clearly related to a successful outcome was age at initiation of therapy [5]. Epelbaum et al., found that efficiency of treatment for strabismic amblyopia decreases with age and it is null by 12 years of age [6]. Children with anisometropic amblyopia have been found to respond to therapy even at a late age [6-8].

Occlusion therapy with patching of the nonamblyopic eye has long been the mainstay of amblyopia treatment $[3,4]$. Initially it was a common belief that occlusion therapy should be prescribed for full time, and that removing the patch even for a short period of time would lead to loss of all the benefits of previous patching. Recently, various amblyopia treatment groups have started to look into the efficacy of part-time occlusion [15-19].

The purpose of this consecutive patient series studied retrospectively was to analyze results of occlusion therapy both full time and part time for strabismic and anisometropic amblyopia in children above six years of age [9-14].

\section{Materials And Methods}

This was a retrospective consecutive case series analysis of children treated for amblyopia in the Drishti The Vision Eye hospital Indore from January 2018 to January 2020. Baseline testing included measurement of Visual Acuity, Cycloplegic Refraction using atropine, and a Complete Orthoptic and Ocular Examination of both eyes. A cycloplegic refraction was carried out using atropine $1 \%$ (children younger than 10 years) or cyclopentolate $1 \%$ (older than 10 years) in the first visit. The children were corrected for refractive error, if any, for at least six weeks prior to inclusion in the study. A difference of two or more lines on Snellen visual acuity chart was used as diagnostic criterion for amblyopia. Only unilateral cases were selected with BCVA of $20 / 20$ in the normal eye. A difference between the spherical equivalents of the two eyes exceeding 2.00 diopter (D) or astigmatism exceeding 1.5 D was considered Anisometropia while amblyopes who had constant Esotropia or Exotropia were classified as Strabismic type.

Children who had been treated with occlusion or had undergone any eye muscle surgery in the past were excluded. The patients were divided into three groups. First group underwent Full Time Occlusion Therapy. Second group was advised Part Time Occlusion Therapy for Six Hours. Third Group was advised Part Time Occlusion Therapy for Less Than six Hours.

Children were followed up monthly to document improvement and record compliance. This treatment was continued till there was no further improvement for at least three consecutive visits or attainment of VA equal to that of the initially dominant eye. 


\section{RESULTS}

This study included 68 eyes of 68 consecutive children who were treated with occlusion between January 2018 to January 2020 . The age at initiation of amblyopia therapy ranged from 6 years to 14 years.
There were 38 males and 30 females. Thirty-two patients had Strabismic Amblyopia and 27 had Anisometropic Amblyopia. Nine patients had a combination of strabismic and anisometropic amblyopia.

\begin{tabular}{|l|l|l|l|}
\hline \multicolumn{3}{|c|}{ Type of Amblyopia } \\
\hline & Strabismic Amblyopia & $\begin{array}{l}\text { Anisometropic } \\
\text { Amblyopia }\end{array}$ & $\begin{array}{l}\text { combination of Strabismic \& } \\
\text { Anisometropic Amblyopia }\end{array}$ \\
\hline Patients & 32 & 27 & 9 \\
\hline
\end{tabular}

\section{Patients}

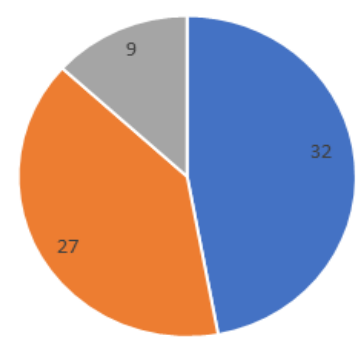

- strabismic amblyopia

- anisometropic amblyopia

n combination of strabismic and anisometropic amblyopia

\begin{tabular}{|l|l|l|}
\hline \multicolumn{3}{|l|}{ Effect of occlusion therapy } \\
\hline & Improvement & No Improvement \\
\hline Patients & 50 & 18 \\
\hline
\end{tabular}

\section{Effect Of Occlusion Therapy}

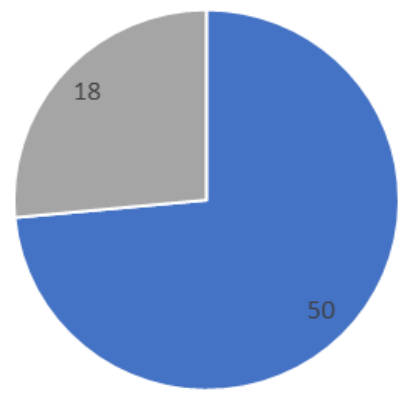

- improvement - - no improvemnet

\begin{tabular}{|l|l|l|l|}
\hline \multicolumn{4}{|l|}{ Patients Undergoing Occlusion Therapy } \\
\hline Age & Total Patient & Improved & No Improvement \\
\hline $6-10$ yrs. & 44 & 40 & 4 \\
\hline $11-14$ yrs. & 24 & 10 & 14 \\
\hline
\end{tabular}




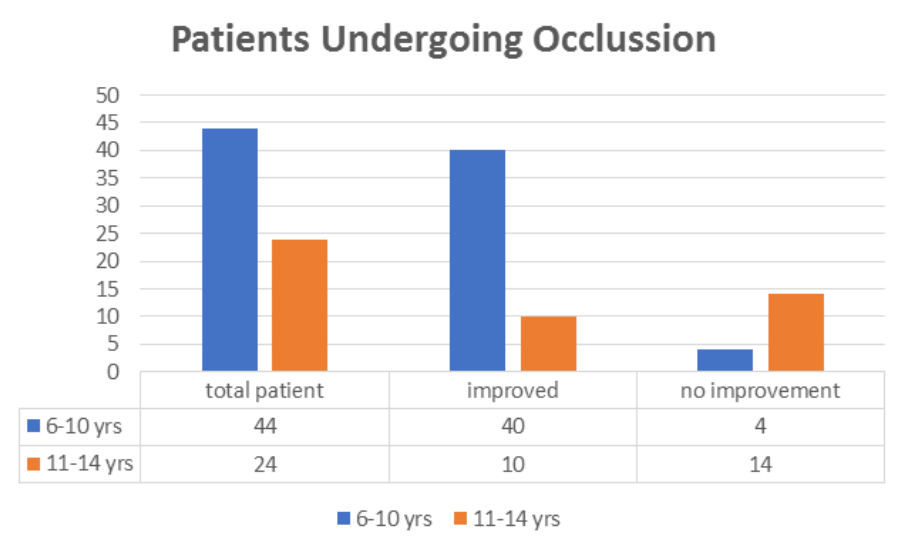

50 out of 68 eyes had improvement in VA.

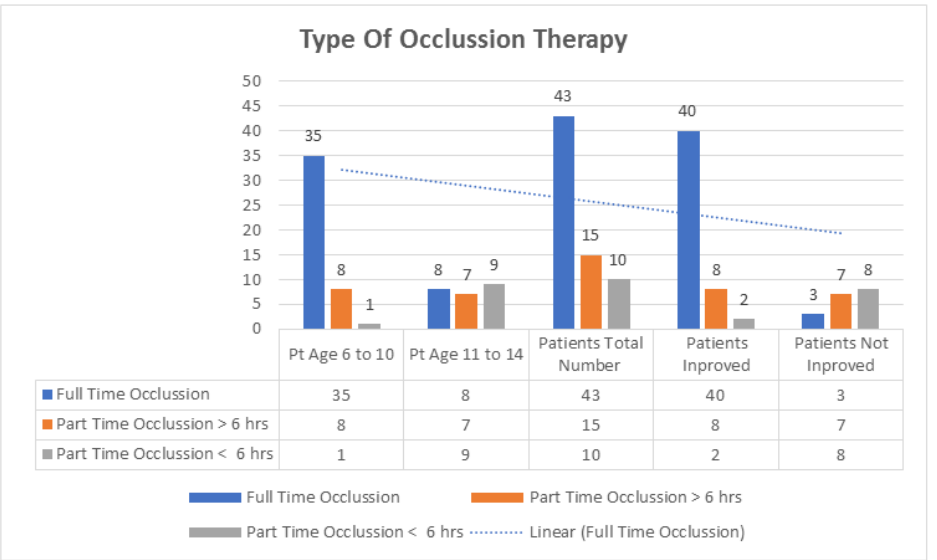

\begin{tabular}{|l|l|l|l|}
\hline Type Of Occlusion Therapy Given \\
\hline & Full Time Occlusion & Part Time Occlusion > 6 hrs. & Part Time Occlusion <6 hrs. \\
\hline Pt Age 6 to 10 & 35 & 8 & 1 \\
\hline Pt Age 11 to 14 & 8 & 7 & 9 \\
\hline Patients Total Number & 43 & 15 & 10 \\
\hline Patients Improved & 40 & 8 & 2 \\
\hline Patients Not Improved & 3 & 7 & 8 \\
\hline
\end{tabular}

\begin{tabular}{|l|l|l|}
\hline \multicolumn{3}{|c|}{ Effect of Age on Treatment Response } \\
\hline Age & Improved & Not Improved \\
\hline $6-10$ yrs. & 40 & 4 \\
\hline $11-14$ yrs. & 10 & 14 \\
\hline
\end{tabular}

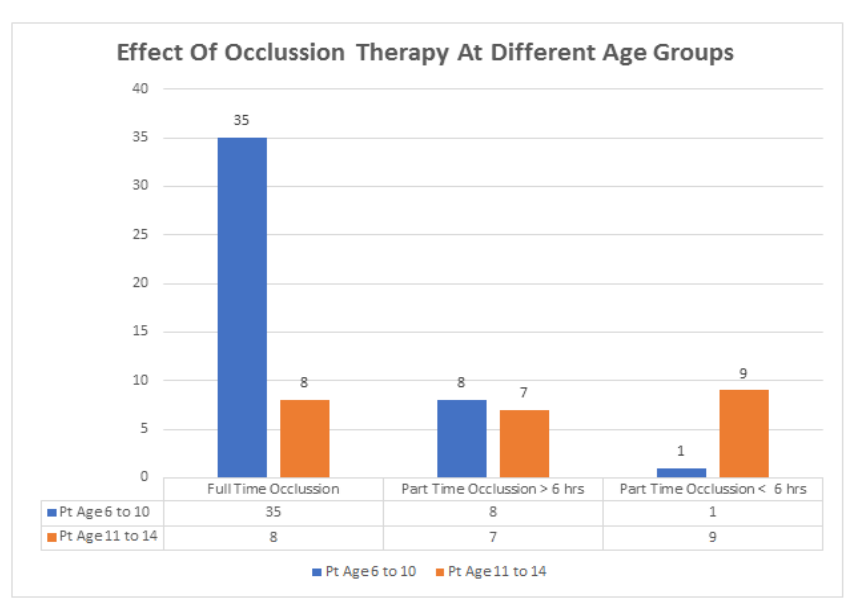




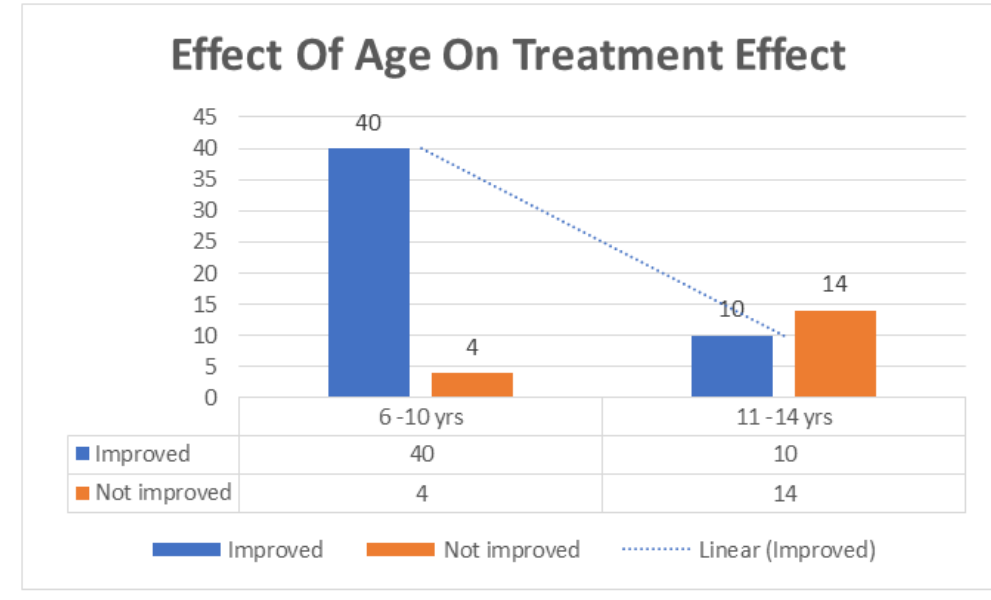

\begin{tabular}{|l|l|l|}
\hline \multicolumn{2}{|l|}{ Effect of Occlusion Therapy on Improvement } \\
\hline & Improvement & No Improvement \\
\hline Full Time occlusion & 40 & 3 \\
\hline Occlusion > 6 hrs. & 8 & 7 \\
\hline Occlusion < 6 hrs. & 2 & 8 \\
\hline
\end{tabular}

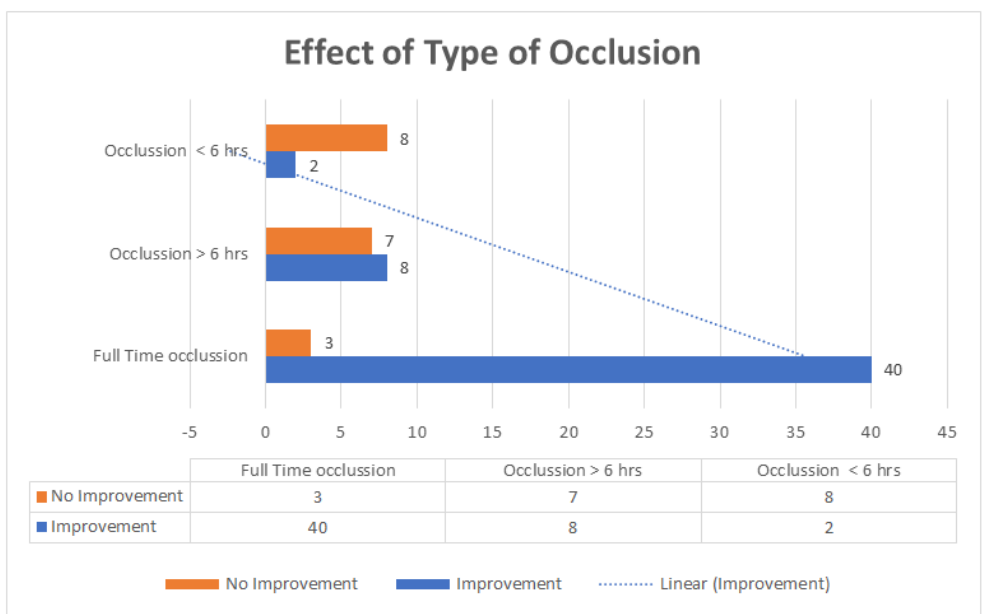

\section{Discussion}

The success of Amblyopia Therapy mainly depends on the Age at initiation of treatment and initial depth of amblyopia in the affected eye [5]. Results of occlusion therapy have been found to be better in younger children [5], but there is ample evidence in literature suggesting benefit of amblyopia therapy in older children $[2,3,7]$. In the present series, 50 out of 68 children had improvement in VA. The result showed that VA could be improved uniformly for strabismic, anisometropic or a combination of Strabismic and Anisometropic Amblyopia in compliant children.

We observed improvement in VA in $90.9 \%$ of children younger than 10 years and $41.6 \%$ of children older than 11 years at the time of initiation of occlusion therapy.

Our result suggests that the children who were younger than 10 years had a significantly better chance of improvement in vision and achieved better bestcorrected final VA than older children.

\section{CONCLUSION}

We observed that both Full-Time Patching and Part-Time Patching led to significant improvement in visual outcome at 18 weeks of treatment even in older age patients though results are less encouraging as age increases more than 10 years. In our study $90.9 \%$ patients in 6-10 year age group improved and only $41.6 \%$ patients improved in 11-14 age group.

Full Time Occlusion may reverse substantial Strabismic Amblyopia in less than 1 month. In contrast, an older child who wears a patch only after school and on weekends may require several months to overcome a moderate deficit. Adherence to occlusion therapy for amblyopia declines with increasing age. However, studies in older children and teenagers with Strabismic or Anisometropic Amblyopia show that treatment can still be beneficial beyond the first decade of life. This is 
especially true in children who have not previously undergone treatment. So, a trial of occlusion should be given to all patients of unilateral amblyopia irrespective of his age.

\section{REFERENCES}

1. Catford GV. Amblyopic occlusion: The results of treatment. Trans Ophthalmol Soc UK. 1967; 87:179-93.

2. Mintz-Hitner HA, Fernandez KM. Successful amblyopia therapy initiated after age 7 years. Arch Ophthalmol. 2000; 118:1535-41.

3. Quah BL, Tay MT, Chew SJ, Lee LK. A study of amblyopia in 18-19 year old males. Singapore Med J. 1991; 32:126-9.

4. Rutstein RP, Fuhr PS. Efficacy and stability of amblyopia therapy. Optom Vis Sci. 1992; 69:74754.

5. Flynn JT, Schiffman J, Feuer W, Corona A. The therapy of amblyopia: An analysis of the results of amblyopia therapy utilizing the pooled data of published studies. Trans Am Ophthalmol Soc. 1998; 96:431-53.

6. Epelbaum M, Milleret C, Buisseret P, Dufier JL. The Sensitive Period for stabismic amblyopia in humans. Ophthalmology. 1993; 100:323-7.

7. Wick B, Wingard M, Cotter S, Scheiman M. Anisometropic amblyopia: Is the patient ever too old to treat? Optom Vis Sci. 1992; 69:866-78.

8. Daw NW. Critical period and amblyopia. Arch Ophthalmol. 1998; 116:502-5.

9. Kasser MD, Feldman JB. Amblyopia in adults. Treatment of those engaged in various industries. Am J Ophthalmol. 1953; 36:1443-6.

10. Vereecken EP, Brabant P. Prognosis for vision in amblyopia after the loss of the good eye. Arch Ophthalmol. 1984; 102:220-4.

11. Oliver M, Neumann R, Chaimovitch Y, Gottesman N, Shimshoni M. Compliance and
Results of treatment for amblyopia in children more than 8 years old. Am J Ophthalmol. 1986; 102:340-5.

12. Pediatric Eye Disease Investigator Group. A prospective, pilot study of treatment of amblyopia in children 10 to $<18$ years old. American journal of ophthalmology. 2004 Mar 1;137(3):581-3.

13. Cleary M. Efficacy of occlusion for strabismic amblyopia: Can an optimal duration be identified? Br J Ophthalmol. 2000; 84:572-8.

14. Scheiman MM, Hertle RW, Beck RW, Edwards AR, Birch E, Cotter SA, Crouch Jr ER, Cruz OA, Davitt BV, Donahue S, Holmes JM. Randomized trial of treatment of amblyopia in children aged 7 to 17 years. Archives of ophthalmology (Chicago, Ill.: 1960). 2005 Apr;123(4):437-47.

15. Pediatric Eye Disease Investigator Group. The course of moderate amblyopia treated with patching in children: experience of the amblyopia treatment study. American journal of ophthalmology. 2003 Oct 1;136(4):620-9.

16. Pediatric eye disease investigator group. A randomized trial of prescribed patching regimens for treatment of moderate amblyopia in children. Arch Ophthalmol. 2003;121:603-11.

17. Holmes JM, Kraker RT, Beck RW, Birch EE, Cotter SA, Everett DF, Hertle RW, Quinn GE, Repka MX, Scheiman MM, Wallace DK. A randomized trial of prescribed patching regimens for treatment of severe amblyopia in children. Ophthalmology. 2003 Nov;110(11):2075-87.

18. Pediatric eye disease investigator group. Impact of patching and atropine treatment on the child and family in the amblyopia treatment study. Arch Ophthalmol. 2003;121:1625-32.

19. Pediatric eye disease investigator group. Randomized trial of treatment of amblyopia in children aged 7-17 years. Arch Ophthalmol. 2005;123:437-47. 